\title{
«ЭФФЕКТ Д.С. МИЛЛЯ»: ПЕРЕГРЕВ ФИНАНСОВОГО РЫНКА И ИНВЕСТИЦИОННЫЙ КОЛЛАПС КАК РЕЗУЛЬТАТ ТЕХНОЛОГИЧЕСКОЙ ТРАНСФОРМАЦИИ ЭКОНОМИКИ
}

\author{
(c) 2020 Лихачев Михаил Олегович
}

доктор экономических наук, доцент, профессор кафедры Экономической теории и менеджмента Московский педагогический государственный университет, Россия, Москва

E-mail: olegmix71@mail.ru

В статье рассматривается концепция снижения нормы прибыли Д.С. Милля как модель специфической реакции рыночной системы на происходящую технологическую трансформацию. Описывается «Эффект Д. С. Милля», заключающийся в том, что резкий рост эффективности производства приводит к такому же резкому повышению объема предложения инвестиционных ресурсов, которое способно снизить ожидаемую доходность от инвестиций настолько, что это блокирует дальнейший инвестиционный процесс и затормозит рост экономики. В статье, также, рассматриваются условия возникновения этого эффекта и возможности его преодоления.

Ключевые слова: промышленная революция, «Эффект Д. С. Милля», технологическая трансформация, экономический рост, накопление капитала, закон понижения нормы прибыли, стагнация

Промышленная революция конца XVIII начала XIX вв. явилась первой глобальной технологической трансформацией, которую пережила рыночная экономика в процессе своего становления и развития. Этот процесс имел сложный и противоречивый характер, сопровождавшийся многими неоднозначными социальными и экономическими последствиями [6]. Эти последствия нашли свое теоретическое отражение в работах классиков политической экономии, которые, либо, как Д. Рикардо или Ж.Б. Сэй, были современниками, непосредственно наблюдавшими эту глобальную трансформацию, либо, как Д.С.Милль, писали свои труды в последующий исторический период, когда отрицательные последствия промышленной революции продолжали оказывать сильное влияние на экономическую и социальную жизнь общества, а положительные еще в полной мере не проявились $[1 ; 5 ; 7 ; 10]$. В результате, классики политической экономии оценивали перспективы развития современных им социально-экономических тенденций весьма пессимистично [4]. С позиции нашего времени эти пессимистические прогнозы можно оценивать как ошибочные. Однако, при этом необходимо учитывать, что классики, в сущности, не анализировали реальные экономические процессы, а пытались моделировать возможные негативные реакции рыночной си- стемы на процесс глобальных технологических изменений. Они рассматривали различные негативные сценарии, которые, при условии известной корректировки в свете новых реалий, могут при определенных условиях рассматриваться как возможный результат реакции рыночной системы на очередную волну технологических изменений, которая может иметь место в будущем. К числу подобных теоретических концепций относится концепция падения нормы прибыли и наступления «стационарного состояния», которая была разработана Д.С. Миллем.

Согласно концепции Д.С.Милля процесс экономического роста и накопления капитала имеет свои внутренние ограничения. Экономический рост генерирует рост дохода и сбережений, которые в свою очередь, трансформируются в инвестиции и вызывают дальнейшее накопление капитала, рост производства, а, следовательно, доходов и сбережений. Однако растущее в результате изобилие капиталов усиливает конкуренцию на рынке капиталов и вызывает снижение нормы прибыли и процентной ставки. Д.С.Милль полагал, что этот процесс не может продолжаться бесконечно, поскольку в сознании населения и потенциальных инвесторов существует представление о некой «минимальной норме прибыли», которая является минимально достаточным стимулом для осуществления 
сбережений и инвестирования. При снижении фактических значений нормы прибыли и процентной ставки ниже этого уровня процесс сбережения и инвестирования прекратиться. А это неизбежно произойдет при непрерывном увеличении изобилия капиталов, которое является прямым следствием экономического роста [8]. Таким образом, можно говорить о своеобразном «эффекте Д.С.Милля», который заключается в том, что быстрая технологическая трансформация создает избыточное предложение инвестиционных ресурсов и снижает их доходность ниже уровня, который является минимально необходимым для дальнейшего стимулирования процессов сбережения и накопления капитала.

Детальное описание этого эффекта содержится в фундаментальной работе Д.С.Милля «Основы политической экономии», IV книга которой непосредственно посвящена анализу проблем долгосрочной экономической динамики капитализма. Модель этой динамики, разработанная Д. С. Миллем, основана на представлении о существовании некоей «минимальной нормы прибыли», которая уравновешивает стремления людей к потреблению и сбережению своего дохода. «В каждый данный момент...,- утверждает Д.С.Милль,- существует определенная минимальная норма прибыли, которая может побудить население ... именно в данное время осуществлять накопления и производительно использовать накопленные средства» [2, с. 52.]. Сбережения и инвестиции продолжают расти и капитал продолжает накапливаться до тех пор, пока фактическая норма прибыли превышает минимальную. Смысл этой теоретической конструкции станет более понятен, если соотнести ее с классической теорией рынка капиталов и процента, рассмотренной в первом параграфе первой главы и Приложении 1. Согласно этой теории величина предложения сбережений определяется высотой ставки процента, а объем спроса на инвестиции определяется разрывом между нормой прибыли и ставкой процента. Предприниматели предъявляют спрос на дополнительные инвестиции до тех пор, пока норма прибыли в реальном производстве превышает ставку процента. Поэтому равновесие на рынке капиталов, определяемое как равенство сбережений и инвестиций, устанавливается тогда, когда ставка процента становится равна норме прибыли в реальном производстве.

Д.С. Милль, в общем, принимает эту класси- ческую модель, однако вносит в нее оригинальную модификацию. Он полагает, что сбережения будут увеличиваться до тех пор, пока ставка процента и средняя норма прибыли в реальном производстве превышают минимальную норму прибыли. Но, если увеличиваются сбережения, то согласно классической теории процента, должны расти и инвестиции. Если рост предложения сбережений не остановится, пока ставка процента не будет равна минимальной норме прибыли, то равенство ставки процента и средней нормы прибыли не будет достигнуто до тех пор, пока средняя норма прибыли не достигнет минимального уровня. Пока средняя норма прибыли будет выше минимального уровня, ставка процента будет ниже средней нормы прибыли, и объем инвестиций будет увеличиваться. Даже если в какой-то момент времени ставка процента окажется равной средней норме прибыли, и объем инвестиций будет временно стабилизирован, предложение сбережений продолжит свой рост, что приведет к снижению ставки процента ниже уровня средней нормы прибыли и возобновлению роста инвестиций [3; 9].

\section{Динамическое равновесие в модели Д. С. Милля}

Исходя из используемого Д.С. Миллем понятия «минимальной нормы прибыли» величину прироста инвестиций можно представить как функцию от разности средней нормы прибыли и ставки процента, а прирост сбережений как функцию от разности ставки процента и минимальной нормы прибыли:

$$
\begin{aligned}
& \mathrm{dI}=f(\mathrm{R}-\mathrm{i}) ; \\
& \mathrm{d} S=\varphi\left(\mathrm{i}-\mathrm{R}_{0}\right) ;
\end{aligned}
$$

где $\mathrm{R}_{0}$ - минимальная норма прибыли. Обе зависимости являются положительными, что означает, что инвестиции продолжают расти до тех пор пока норма прибыли превышает процентную ставку, что создает положительную предпринимательскую прибыль, а сбережения продолжают расти пока процентная ставка превышает «минимальную норму прибыли», то есть доходность сбережений является выше минимального уровня, при котором сохраняется стимул для сбережения части дохода.

Представив эти зависимости в линейной форме, и учитывая, что в состоянии равновесия 
приросты сбережений и инвестиций должны быть равны нулю, можно записать простейшую систему из двух линейных уравнений:

$$
\begin{aligned}
& c(\mathrm{R}-\mathrm{i})=0 ; \\
& \mathrm{k}\left(\mathrm{i}-\mathrm{R}_{0}\right)=0 ;
\end{aligned}
$$

где с и $\mathrm{k}$ - постоянные положительные коэффициенты. Очевидно, что эта система будет иметь единственное решение при $\mathrm{i}=\mathrm{R}=\mathrm{R}_{0}$. Следовательно, равновесие на рынке капитала и в масштабах экономики устанавливается только тогда, когда средняя норма прибыли достигает минимального значения, которое уже не стимулирует дальнейший рост сбережений и инвестиций.

Д.С.Милль рассматривает два возможных варианта приближения средней нормы прибыли к минимальному уровню. Первый вариант предполагает ускоренное накопление капитала при стабильной или сравнительно медленно возрастающей численности населения, что ведет к повышению номинальной и реальной заработной платы. В этом случае «... больший по размерам капитал будет распределен в виде заработной платы между прежним числом работников. Поскольку количество труда не увеличилось и не было сделано каких-либо улучшений, повышающих его эффективность, то не произойдет какого-либо увеличения продукта; ...в подобной ситуации прибыли в кратчайший срок упадут до такой степени, что прекратится дальнейший рост капитала» [2, с. 58.]. Второй вариант предполагает, что рост населения компенсирует накопление капитала, блокируя тенденцию повышения номинальной и реальной заработной платы, однако рост номинальной заработной платы происходит в связи с повышением спроса на сельскохозяйственную продукцию. «При отсутствии каких-либо усовершенствований в промышленном производстве,- утверждает Д.С.Милль, - этот спрос может удовлетворяться только путем либо использования худших участков земли, либо путем более сложной и дорогостоящей обработки участков, уже используемых для производства сельскохозяйственной продукции» [2, с. 58.]. Этот вариант развития экономики был в достаточной степени разработан предшественником Д.С. Милля - Д.Рикардо. Д. С. Милль использует его, чтобы показать, что и в этом случае неизбежно произойдет снижение средней нормы прибыли за счет роста цен на сельскохозяйственную продукцию и вызванное этим повышение номинальной заработной платы.

Таким образом, Д.С.Милль полагает, что тенденция средней нормы прибыли к минимальному уровню, прекращающему накопление капитала, действует непрерывно. «Рост капитала,- утверждает он,- достиг бы в ближайшем будущем своего предела, если бы этот предел постоянно не отодвигался, и не возникало новых возможностей для роста» [2, с. 58.]. В качестве тенденций, противодействующих падению средней нормы прибыли до минимального уровня, Д.С. Милль рассматривает обесценение части капиталов в период торговых кризисов, совершенствование технологии производства, импорт дешевых товаров и экспорт капитала. Однако действие этих тенденций, по мнению Д.С.Милля лишь отодвигают момент, когда норма прибыли зафиксируется на своем минимальном уровне и процесс накопления капитала остановится: «...увеличение богатства не беспредельно и в конце ... находится состояние застоя» [2, с. 76.].

Очевидно, что в своей теории снижения нормы прибыли до минимального уровня Д.С. Милль воспроизводит в модифицированном виде модель краткосрочного макроэкономического равновесия, разработанную классиками на базе «Равенства Сэя». Благодаря введению в эту модель понятия «минимальной нормы прибыли», Д.С.Милль определяет краткосрочное макроэкономическое равновесие или в его терминологии,- состояние застоя, как состояние, к которому экономическая система тяготеет в каждый данный момент времени при прочих равных условиях (при данной численности рабочего населения, уровне производительности и капиталовооруженности труда). Однако Д.С. Милль на этом не останавливается. Вводя в анализ противодействующие тенденции, он закладывает основы для формирования теории долгосрочного макроэкономического равновесия, обеспечивающего непрерывное накопление капитала и рост производства. Таким образом, долгосрочное равновесие определяется как состояние, в котором тенденция снижения средней нормы прибыли и противодействующие ей тенденции взаимно компенсируют друг друга. 


\section{Формализованная модель «эффекта Д. С. Милля»}

Условием сохранения долгосрочного равновесия является поддержание положительной разности между средней нормой прибыли в экономике и ставкой процента. Причем, ставка процента при этом будет определяться в диапазоне между фактической и минимальной нормой прибыли. Для того, чтобы при этом экономика в каждый данный момент времени находилась в состоянии равновесия нужно, чтобы в каждый данный момент времени сбережения были равны инвестициям, а для этого должны быть равны их приросты в единицу времени. Это равенство обеспечивается установлением равновесного уровня ставки процента, который для системы с линейными зависимостями прироста инвестиций от разности фактической средней нормы прибыли и ставки процента и прироста сбережений от разности ставки процента и минимальной нормы прибыли, может быть определен на основе следующего уравнения:

$$
d I-d S=c(R-i)-k\left(i-R_{0}\right)
$$

Решением этого уравнения для ставки процента при dI - dS = 0 будет следующее выражение:

$$
\mathrm{i}=\frac{\left(c+k \frac{R_{0}}{R}\right)}{(\mathrm{c}+\mathrm{k})} \mathrm{R} ;
$$

Эта ставка процента обеспечивает равновесие на рынке капитала, при котором сбережения и инвестиции растут одинаковыми темпами и краткосрочное равновесие, поддерживаемое в экономике в каждый данный момент времени, оказывается совместимым с долгосрочным равновесием. Нетрудно заметить, что поскольку фактическая средняя норма прибыли превышает минимальную, ставка процента также будет ниже фактической средней нормы прибыли. Ставка процента будет равна фактической средней норме прибыли только в том случае, если последняя принимает свое минимальное значение. Если же фактическая норма прибыли выше минимальной, будет существовать положительная разность между фактическим значением средней нормы прибыли и ставкой процента, и инвестиции будут возрастать. При условии, что предложение труда, то есть численность рабочего населения будет неизменной, а капиталовооруженность труда постоянной, все до- полнительные инвестиции будут полностью израсходованы на увеличение заработной платы:

$$
\mathrm{dw} / \mathrm{p}=\frac{\mathrm{c}}{\mathrm{L}}(\mathrm{R}-\mathrm{i})=\frac{\mathrm{c}}{\mathrm{L}}\left(1-\frac{\mathrm{c}+\mathrm{k} \frac{\mathrm{R}_{0}}{\mathrm{R}}}{\mathrm{c}+\mathrm{k}}\right) \mathrm{R}
$$

Воздействие изменения реальной заработной платы на величину средней нормы прибыли можно выразить как:

$$
\mathrm{dR}=-\frac{(1+\mathrm{R})}{(\mathrm{K}(1 / \mathrm{p}) / \mathrm{L}+\mathrm{w} / \mathrm{p})} \frac{\mathrm{c}}{\mathrm{L}}\left(1-\frac{\mathrm{c}+\mathrm{k} \frac{\mathrm{R}_{0}}{\mathrm{R}}}{\mathrm{c}+\mathrm{k}}\right) \mathrm{R}
$$

Очевидно, что снижение нормы прибыли будет продолжаться до тех пор, пока она не снизится до минимального уровня, ограничивающего рост накопления капитала. Только в этом случае изменения реальной заработной платы и нормы прибыли обращаются в ноль. Это и есть тенденция прибыли к минимальному уровню, которую рассматривает Д. С. Милль. Из всех факторов, которые, согласно теории Д.С. Милля могут сдерживать эту тенденцию, устойчивое противодействие ей может оказывать только повышение производительности труда, прочие факторы (обесценение капитала в период кризисов, экспорт капитала и импорт дешевых товаров) могут оказывать только эпизодическое воздействие и, следовательно, не способны обеспечить поддержание долгосрочного равновесия. Однако, нужно учесть, что повышение производительности труда, как правило, неразрывно связано с ростом его капиталовооруженности, то есть с увеличением затрат капитала в расчете на единицу рабочей силы. Д. С. Милль не акцентировал на этом своего внимания, но этот момент представляется важным для развития его теории в концепцию долгосрочного равновесия.

Смягчение «эффекта Д.С. Милля» за счет роста производительности труда с учетом роста капиталовооруженности

Повышение затрат капитала в расчете на одного занятого работника оказывает двоякое воздействие на величину средней нормы прибыли.

Во-первых, рост капиталовооруженности труда приводит к сокращению доли дополнительных инвестиций, которые непосредственно увеличивают спрос на труд, и при неизменной численности рабочего населения вызывают по- 
вышение уровня реальной заработной платы. Поэтому прирост инвестиций с учетом повышения уровня капиталовооруженности труда может быть записан как:

$$
\mathrm{dI}=\Delta \mathrm{K}(1 / \mathrm{p})+\mathrm{L} \Delta \mathrm{w} / \mathrm{p}
$$

Откуда прирост заработной платы в результате увеличения инвестиций может быть определен как:

$$
\mathrm{dw} / \mathrm{p}=-\frac{\Delta \mathrm{K}(1 / \mathrm{p})}{\mathrm{L}}+\frac{\mathrm{c}}{\mathrm{L}}\left(1-\frac{\mathrm{c}+\mathrm{k} \frac{\mathrm{R}_{0}}{\mathrm{R}}}{\mathrm{c}+\mathrm{k}}\right) \mathrm{R}
$$

Очевидно, что в условиях повышения капиталовооруженности труда, рост заработной платы будет меньше, чем в случае, когда весь дополнительный капитал полностью обращается увеличением спроса на труд.

Во-вторых, повышение капиталовооруженности труда вызывает прирост его производительности, и тем самым сдерживают падение нормы прибыли в условиях возрастания реальной заработной платы. Если предположить, что между уровнем капиталовооруженности труда и уровнем его производительности существует линейная зависимость, то прирост производительности труда может быть записан как:

$$
\mathrm{dY} / \mathrm{L}=\mathrm{b} \frac{\Delta \mathrm{K}(1 / \mathrm{p})}{\mathrm{L}}
$$

где $\mathrm{b}$ - постоянный коэффициент, характеризующий данную зависимость.

Поскольку стоимость продукта в классической теории складывается из затрат капитала и оплаты труда, производительность труда можно представить как:

$$
\mathrm{Y} / \mathrm{L}=(\mathrm{aK}(1 / \mathrm{p}) / \mathrm{L}+\mathrm{w} / \mathrm{p})(1+\mathrm{R})
$$

Продифференцировав это выражение по значениям нормы прибыли и заработной платы, получим:

$$
\mathrm{dY} / \mathrm{L}=(\mathrm{K}(1 / \mathrm{p}) / \mathrm{L}+\mathrm{w} / \mathrm{p}) \Delta \mathrm{R}+(1+\mathrm{R}) \Delta \mathrm{w} / \mathrm{p}
$$

Подставив это выражение к (11) и выразив оттуда изменение нормы прибыли, можно получить выражение, позволяющее определить условия долгосрочного равновесия экономической системы в модели Д.С. Милля:

$$
\mathrm{dR}=\frac{\mathrm{b} \Delta \mathrm{K}(1 / \mathrm{p})-(1+\mathrm{R}) \mathrm{L} \Delta \mathrm{w} / \mathrm{p}}{(\mathrm{K}(1 / \mathrm{p}) / \mathrm{L}+\mathrm{w} / \mathrm{p})}
$$

Равновесное значение прироста капитала можно представить как:

$$
\mathrm{dK}(1 / \mathrm{p})=\frac{(1+\mathrm{R}) \mathrm{L} \Delta \mathrm{w} / \mathrm{p}}{\mathrm{b}}
$$

Или после подстановки (10) в 15:

$$
d K(1 / p)=\frac{(1+R) c}{\left(1+\frac{b}{R}\right)}\left(1-\frac{c+k \frac{R_{0}}{R}}{c+k}\right) R:
$$

Если же подставить это значение в (10), можно получить равновесное значение прироста реальной заработной платы:

$$
d w / p=\left(1-\frac{1+R}{1+\frac{b}{R}}\right) \frac{c}{L}\left(1-\frac{c+k \frac{R_{0}}{R}}{c+k}\right) R
$$

Причем если подставить равновесные значения проростов капитала и заработной платы в (9) станет очевидным, что величина

$$
\frac{1+R}{1+\frac{b}{R}}
$$

представляет равновесную долю накопления капитала в общем приросте инвестиций, которая позволяет сохранить сложившуюся норму прибыли. Она находится в обратной зависимости от $\mathrm{b}$ - величины, определяющей влияние капиталовооруженности труда на его производительность (при этом, чтобы долгосрочное равновесие возможно только если $\mathrm{b} \geq \mathrm{R}^{2}$ ).

При соблюдении этих условий прирост капиталовооруженности и производительности труда будет полностью компенсировать прирост реальной заработной платы, норма прибыли будет оставаться на прежнем уровне, и инвестиции будут продолжать свой рост. Объем национального производства при этом также будет увеличиваться по мере повышения производительности труда, то есть установится состояние устойчивого сбалансированного роста. Разумеется, сам Д.С.Милль считал такое состояние недостижимым, наоборот он полагал, что устойчивым может быть только состояние застоя, в котором 
накопление капитала и экономический рост прекратятся. Однако, как было показано выше, сформированная Д.С.Миллем модель экономической динамики легко трансформируется в модель сбалансированного роста, то есть в модель долгосрочного равновесия.

Тем не менее следует отметить, что условия сбалансированного роста, которые позволяют избежать «Эффекта Д.С. Милля» достаточно сложны для того, чтобы они могли автоматически поддерживаться в процессе реального развития экономики, переживающей процесс интенсивных технологических трансформаций. Смысл проведенного анализа, скорее, заключается в том, чтобы показать, что в основе «Эффекта Д. С. Милля» лежит не сам по себе возросший поток инвестиционных ресурсов, соз- данный процессом технологической трансформации и ростом эффективности производства, сколько его структурная несбалансированность. При соблюдении, выявленных в нашем анализе пропорций, этот поток мог бы способствовать дальнейшему стимулированию экономического роста без снижения нормы прибыли. Таким образом, можно утверждать, что, описанный Д. С. Миллем негативный эффект, вызываемый резким ростом сбережений и предложения инвестиционных ресурсов, может быть если не полностью нивелирован, то по крайней мере значительно ограничен за счет регулирующей политики государства, способной поддержать структурную сбалансированность инвестиционного процесса.

\section{Библиографический список}

1. Блауг М. Экономическая мысль в ретроспективе. М.: Дело ЛТД.,1994.

2. Милль Д. С. Основы политической экономии. Т. 3. М., 1981.

3. Негиши Т. История экономической теории.-М., 1995.

4. Розанваллон П. Утопический капитализм. М.: Новое литературное обозрение, 2007.

5. Шумпетер Й. История экономического анализа. Т. 2. СПб.: «Экономическая школа», 2001.

6. Canterbey E. R. A brief history of economics. London, 2001.

7. Heilbroner R. L. The worldly philosophers. New York, 1999.

8. Mill J. S. Essays on some unsettled questions of Political Economy. London, 1844.

9. Okishio N. Technical Change and the Rate of Profit // Kobe University Economic Review. 1961. Vol. 7. P. 85-99.

10. Robbins L. A History of Economic Thought. Princeton and Oxford, 1998. 